\title{
BI-INTERIOR IDEALS OF SEMIGROUPS
}

\author{
M. Murali Krishna RaO \\ Department of Mathematics \\ GIT, GITAM University \\ Visakhapatnam - 530 045, Andhra Pradesh, India \\ e-mail: mmarapureddy@gmail.com
}

\begin{abstract}
In this paper, as a further generalization of ideals, we introduce the notion of bi-interior ideal as a generalization of quasi ideal, bi-ideal and interior ideal of semigroup and study the properties of bi-interior ideals of semigroup, simple semigroup and regular semigroup.
\end{abstract}

Keywords: quasi ideal, bi-ideal, interior ideal, bi-interior ideal, bi-quasi ideal, regular semigroup, bi-interior simple semigroup.

2010 Mathematics Subject Classification: 20M17, 06F05.

\section{REFERENCES}

[1] R.A. Good and D.R. Hughes, Associated groups for a semigroup, Bull. Amer. Math. Soc. 58 (1952) 624-625.

[2] K. Iseki, Quasi-ideals in semirings without zero, Proc. Japan Acad. 34 (1958) 79-84.

[3] W. Jantanan and T. Changphas, On 0-minimal (0,2)-bi-ideals, Quasigroups and Related Systems 21 (2013) 83-90.

[4] S. Lajos, On the bi-ideals in semigroups, Proc. Japan Acad. 45 (1969) 710-712.

[5] S. Lajos and F.A. Szasz, On the bi-ideals in associative ring, Proc. Japan Acad. 46 (1970) 505-507.

[6] P. Palakawongna Ayutthaya and B. Pibaljommee, Characterizations of ordered $k$ regular semirings by ordered quasi k-ideals, Quasigroups and Related Systems 25 (2017) 109-120.

[7] M.M.K. Rao, Bi-quasi-ideals and fuzzy bi-quasi ideals of $\Gamma$-semigroups, Bull. Int. Math. Virtual Inst. 7 (2017) 231-242. 
[8] A.M. Shabir and A. Batod, A note on quasi ideal in semigroups, Southeast Asian Bull. Math. 7 (2004) 923-928.

[9] O. Steinfeld, Uher die quasi ideals, Von halbgruppend Publ. Math., Debrecen 4 (1956) 262-275.

Received 18 October 2017

Revised 2 December 2017

Accepted 17 january 2018 